\title{
Cultural and Pathogenic Variability among the Isolates of Sclerotium rolfsii Causing Stem Rot of Chilli (Capsicum annuum L.)
}

\author{
Prem Naresh*, Ved Ratan, S. K. Biswas, Virendra Kumar and Upesh Kumar
}

Dept. of Plant Pathology, C. S. Azad University of Agriculture and Technology, Kanpur, Uttar Pradesh (208 002), India

\section{Corresponding Author}

Prem Naresh

e-mail: samirkrbiswas@rediffmail.com

\author{
Article History \\ Manuscript No. AR1684a \\ Received in $10^{\text {th }}$ Sep, 2016 \\ Received in revised form $19^{\text {th }}$ Jan, 2017 \\ Accepted in final form $7^{\text {th }}$ Feb, 2017
}

\begin{abstract}
Variability among ten isolates of S. rofsii collected from different locations of chilli host is reported during 2009-10 and 2010-11 and these isolates varied in different Cultural characters likes' colony diameter, no. of slerosia plate ${ }^{-1}$, colony character (colony appearance and colony colour) and sclerotial behaviar. In cultural variability, out of ten isolates of $S$. rofsii have revealed that maximum mycelial growth of 88.0 $\mathrm{mm}$. was obtained on SR1 (Sarsaul) isolate followed by SR9 (Maudaha) isolate which was statistically at par with each other. The lowest mycelial growth of $79.0 \mathrm{~mm}$ was recorded in SR6 (Kucharia) isolate. It has also found that most of the isolates were produced sclerotia on large scale ( $>400$ sclerotia plate $^{-1}$ ), while some isolates were produced $<300$ sclerotia plate $^{-1}$. The colony appearance from fluffy (SR1, SR2, SR3, SR4, SR8, SR9 and SR10) to compact (SR5, SR6 and SR7) while colony colours were dark brown, the sclerotial shapes were round while colours of sclerotia were light brown (SR1, SR2, SR3 and SR4) to dark brown (SR5, SR6 and SR7) and brown (SR8, SR9 and SR10). Sclerotial patterns were scarred to and groups. In pathogenic variability, among the ten isolates were also exist among the isolates representing the incidence of stem rot was recorded after one month of seedling 33.33-57.57\% seedling mortality. The highest mortality (57.57\%) was recorded in the isolates of (SR1) Sarsaul, Kanpur location and minimum 33.33\% in the isolates of (SR5) Mallavan district, Hardoi.
\end{abstract}

Keywords: Chilli, Sclerotium rolfsii, disease incidence, Cultural, pathogenic variability

\section{Introduction}

The chilli (Capsicum annuum L.) also known as Mircha is an important spice and vegetable crop belonging to the family Solanaceae. In India, chilli is grown in almost all the states of the country. However, the major chilli growing states in terms of production are Andhra Pradesh (49\%), Karnataka (15\%), Orissa (8\%), Maharashtra (6\%), West Bengal (5\%), Rajasthan (4\%) and Tamil Nadu (3\%) (Kochi, 2005). In India, area, production and productivity of chilli were 767.23 mha. $1202.94 \mathrm{mt}$ and $1.6 \mathrm{mt} \mathrm{ha}^{-1}$, respectively (Parthasarathy and Kandiannan, 2010). However, in the background of increasing population pressure there is a need to increase more productive from same pieces of land but the crop is suffered from a number of abiotic and biotic factors like's fungi, bacteria, viruses, nematodes etc. However major losses of chilli are covered by fungal diseases. Among fungal diseases, stem rot of chilli caused by Sclerosium rolfsii Sacc is an important disease in India which is also known as foot rot/ Southern blight/white stem rot/stem rot in different places of the country. The pathogen is well known polyphagous, omnivorous, ubiquitous and most destructive soil borne fungus in tropical and subtropical countries where high temperature prevails during the rainy season (Weber, 1931). The disease is appeared in all the stages of crop from nursery to maturity stages and all parts of the plants are affected by the pathogen. Chilli is highly susceptible to the disease and causing 50 to $60 \%$ seedling mortality (Lukose et al., 2003). They reported that $30-40 \%$ seedling rot was observed at farmer's field in Saurashtra Gujrat of the country. Recently, the incidence of the disease is gradually increasing in different agro-climatic regions of Uttar Pradesh. Since Sclerotium rolfsi is a polyphagous pathogen infecting different types of crop and in different areas. Considering the point of view that the variability may exist among the isolates Therefore, study was under taken to find out the cultural and pathogenic variability amongest the isolates.

\section{Materials and Methods}

\subsection{Collection of diseased material}

Naturally infected plant parts of chilli showing characteristic symptoms were collected at regular intervals from Kalayanpur, Sarsaul (Kanpur Nagar), Ghatampur (Ramabai Nagar), Bindki (Fatehpur), Ajgain. (Unnao), Chamad (Aligarh), Mallanwa (Hardoi), Kucharia (Raebarelly), Maudaha (Hamirpur) and 
Barokhar (Banda) during 2009-10 and 2010-2011. The diseased specimens were brought to the laboratory and examined thoroughly for the presence of causal organism and further investigations.

\subsection{Survey for recording disease incidence}

Total five fields from each ten locations of Uttar Pradesh were surveyed from June to March during 2009-10 and 2010-11. One hundred randomly selected plants from each field were collected at seedling to maturity stage. The disease incidence of stem rot of chilli was observed by randomly selected four sub plots of four square meters in different field and counted the number of diseased and healthy plants. The per cent disease incidence (PDI) was calculated according to fallowing procedure as given by Chestler (1950)

$$
\begin{gathered}
\text { No. of diseased } \\
\text { plants in sub plot } \\
\text { Percentage disease incidence (PDI) }=\begin{array}{c}
\text { Total no. of plants } \\
\text { in sub plot }
\end{array}
\end{gathered}
$$

\subsection{Isolation and purification of the fungus}

Infected plant stems, showing distinct symptoms were selected for isolation of the pathogen. The selected stems were thoroughly washed with tap water, in order to remove dust and other surface contaminants. Small pieces from the affected stems just touching the healthy portion of stems were cut with a sterilized blade. The cut pieces were gently washed with distilled water and then dipped in $0.1 \%$ mercuric chloride solution for 30 second. These pieces were taken out and washed immediately with 3-4 times with sterile water, to remove traces of mercuric chloride. The excess moisture was removed by drying the pieces in between the two folds of sterilized blotting paper. The sterilized pieces were then transferred into Petri dishes containing two per cent potato dextrose agar (PDA) medium with the help of sterilized forceps. Then it was kept in the inoculation chamber. As soon as the mycelial growth was visible around the pieces, fungal tips from the growing mycelium were transferred to the sterilized culture tubes containing $2.0 \%$ potato dextrose agar medium. Isolation was done separately from each sample. The culture of isolates were maintained in culture tubes by sub-culturing at every two months interval regularly and kept in refrigerator at $28 \pm 1{ }^{\circ} \mathrm{C}$ separately. The each isolates of the pathogen was identified by the microscopic examination on the basis of mycelial and colonial characters like nature of growth, septation, branching pattern, colouration and width of the hyphae, etc. and sclerotial characters likes colour, size, shape and nature .

\subsection{Variability among the isolated pathogen}

\subsubsection{Cultural variability among isolated pathogens}

To determine the cultural behavior of different isolates, 20 $\mathrm{ml}$ sterilized Potato Dextrose Agar medium was poured in sterilized Petri dishes of $9 \mathrm{~cm}$ diameter. After solidification of medium in each Petri dish, it was inoculated with 5.00 $\mathrm{mm}$ disc from 7 days old cultures and incubated at $20 \pm 1{ }^{\circ} \mathrm{C}$ for 7 days. After seven days of inoculation the radial growth was measured in $\mathrm{mm}$ in two directions at right angles to each other and average was calculated. Cultural characteristics viz. colony type, colony color and aerial mycelium were also recorded after 7 days of inoculation. The number of sclerotia colony ${ }^{-1}$ was counted after 15 days of inoculation. The experiment was replicated thrice.

\subsubsection{Pathogenic variability among isolated pathogen}

The experiment was conducted in the glass house conditions in pots. Sterilized loam soil, which was previously disinfected with $5 \%$ solution of formalin was filled in earthen pots and irrigated to provide adequate moisture. The inoculums were prepared by growing pure culture of Sclerotium rolfsii on sand+corn meal for 10 days and inoculation of the soil was done seven days before sowing of seeds by mixing of the soil with fungal culture in pots. The inoculum of the pathogen was added @ $5 \%$ of weight of the soil in pots. Control pots were filled with soil without adding any inoculums. Healthy and surface sterilized seeds of the chilli variety Kalyanpur Chaman was first disinfected with $2.5 \%$ sodium hypo-chloride solution for 3 minutes and then rinsed with sterilized water, dried and sown @ 40 seeds pot ${ }^{-1}$. The pots were then incubated in glass house at $28 \pm 1{ }^{\circ} \mathrm{C}$ and irrigated regularly to maintain sufficient moisture. Three replications of each treatment were maintained. The pots were kept in glass house and were observed critically for seedling emergence and appearance of symptoms on seedlings and adult plants up to 45 days of sowing. The percentage of pre-emergence and post-emergence infection was calculated from the number of seedlings that failed to grow and the number of infected plants, respectively.

\section{Results and Discussion}

The present investigations were carried out on the morphological and pathogenic variability of Sclerotium rolfsii causes stem rot of chilli find and the findings are as below.

\subsection{Cultural variability}

The different isolates of $S$. rolfsii under present study were grown on natural PDA media for their growth and sclerotial production. The data were presented in Table 1 showed that cultural variability like fungal growth, colony character and sclerotia.

Sclerotial productions were exist among the isolates. It has found that maximum mycelial growth $(88.0 \mathrm{~mm})$ was obtained on SR1 isolate followed by SR9 isolate which were also statistically at par to each other (Table 1). The lowest mycelial growth $(79.0 \mathrm{~mm})$ was recorded on SR6 isolate. The rest of the isolates (SR3, SR5 and SR4) were not significantly different with each other in case of their growth pattern.

The colony characters were quite distinct on different isolates. 


\begin{tabular}{|c|c|c|c|c|c|c|c|}
\hline \multirow[t]{2}{*}{ Isolates (with location ) } & \multirow{2}{*}{$\begin{array}{l}\text { Average } \\
\text { diameter of } \\
\text { colony } \\
\text { after } 7 \text { days } \\
(\mathrm{mm})\end{array}$} & \multirow{2}{*}{$\begin{array}{c}\text { No. of } \\
\text { sclerotia } \\
\text { formed } \\
\text { after } 15 \\
\text { days } \\
\text { mean }\end{array}$} & \multicolumn{2}{|c|}{ Colony characters } & \multicolumn{2}{|c|}{ Sclerotial character } & \multirow{2}{*}{$\begin{array}{l}\text { Pattern of } \\
\text { sclerotial } \\
\text { formation }\end{array}$} \\
\hline & & & $\begin{array}{l}\text { Colony } \\
\text { character }\end{array}$ & Colour & Shape & colour & \\
\hline SR1 Sarsaul, Kanpur & 88 & 410 & Fluffy & Dark brown & Round & Light brown & Bunch \\
\hline SR2 Ghatampur, Ramabainagar & 85 & 446 & Fluffy & Dark brown & Round & Light brown & Bunch \\
\hline SR3 Bindaki, Fatehpur & 86 & 410 & Fluffy & Dark brown & Round & Light brown & Bunch \\
\hline $\begin{array}{l}\text { SR4 Veg. Res.Farm Kalyanpur } \\
\text { Kanpur }\end{array}$ & 85 & 430 & Fluffy & Dark brown & Round & Light brown & Bunch \\
\hline SR5 Mallawa , Hardoi & 86 & 420 & compact & Dark brown & Round & Dark brown & Scattered \\
\hline SR6 Kucharia, RaeBareli & 79 & 435 & compact & Dark brown & Round & Dark brown & Scattered \\
\hline SR7 Ajgain, Unnao & 81 & 340 & compact & Dark brown & Round & Dark brown & Scattered \\
\hline SR8 Chamad, Aligarh & 82 & 336 & Fluffy & Dark brown & Round & brown & Group \\
\hline SR9 Maudaha, Hamirpur & 87 & 220 & Fluffy & Dark brown & Round & brown & Group \\
\hline SR10 Barokhar, Banda & 85 & 228 & Fluffy & Dark brown & Round & brown & Group \\
\hline$C D(p=0.05)$ & 17.15 & & & & & & \\
\hline SEm \pm & 5.77 & & & & & & \\
\hline
\end{tabular}

The colony was excellent, fluffy in SR1, SR2, SR3, SR4, SR8, SR9 and SR10 isolates and compact in isolates of SR5, SR6 and SR7. As far as colour of fungal colony is concerned they showed their colour from light brown to dark brown colour (Figure 1). The colonies of isolate SR1, SR2, SR3 and SR4 showed light brown colour and SR5, SR6 and SR7 are dark brown colony. However, the colony colour of SR8, SR9 and SR10 were of brown in colour. Similarly, SR2 isolate was best for sclerotial productions (446) which were followed by isolate SR6 (435). Least sclerotial production with 220 was observed on isolate SR9. The characteristics of the sclerotia were also studied and found that, the shape of sclerotia produced by all isolates were round and the color of these sclerotia were light brown in SR1, SR2, SR3 and SR4, brown in SR8, SR9 and SR10 and remains SR5, SR6 and SR7 were dark brown. Regarding sclerotial formation, it was found that the maximum sclerotia were formed (446) in the isolate of Ghatampur (Ramabai Nagar) fallowed by isolates (435) of Kucharia (Rae Bareli). The shape of sclerotia was round in all the isolates whereas, colour of sclerotia differed from light brown to brown and dark brown in the isolate of SR5, SR6 and SR7.

The pattern of sclerotial formation were formed in concentric rings and bunches in the isolate of SR1, SR2, SR3 and SR4 whereas, sclerotia were formed in scattered form in the isolates of SR5, SR6 and SR7 whereas, isolates SR8, SR9 and SR10 showed sclerotial formation in groups. Prabhu and Patil (2005) assessed morphological, biochemical and pathogenic variations among twelve isolates of $S$. rolfsii occurring on soyabean and found a significant difference with respect to all morphological characters like, colour of sclerotia ranged from brown to chocolates brown, shape ranged from spherical to sub spherical, diameter and test weight etc. Serra et al. (2005) evaluated the biological and physiological characterization of Sclerotium rolfsii causing sclerotium wilt obtained from green pepper in the state of Maranhao. Akram et al. (2007) worked on the variability among twelve isolates of Sclerotium rolfsii Sacc. collected from various localities of chickpea growing areas of Punjab province of Pakistan and reported that the isolates showed variability in colony morphology, mycelial growth rate, sclerotium formation and sclerotial size and colour. Darakhshanda et al. (2007) also reported that, different strains of Sclerotium rolfsii produced round shaped sclerotia with average diameter of $0.5-2.0 \mathrm{~mm}$.

\subsection{Pathogenic variability}

The results in the Table 2 revealed that there was no adverse effect of $S$. rolfsii isolates on the seed germination of chilli. The germination of seed ranged from 77.50 to $90.0 \%$. The pre germination disease incidence was highest $(22.5 \%)$ in isolate of SR3 (Bindaki, Fatehpur) and it was lowest (10\%) in isolate of SR6 (Kucharia, Rae Bareli) and SR2 (Ghatampur, Ramabai Nagar). Similarily seedling vigour after 30 days of sowing showed that plant height ranges from 18.0-19.75 $\mathrm{cm}$ with average means $18.87 \mathrm{~cm}$ in all $S$. rolfsii isolates treatment. The incidence of stem rot was recorded after one month of planting and the result showed that the seedling 

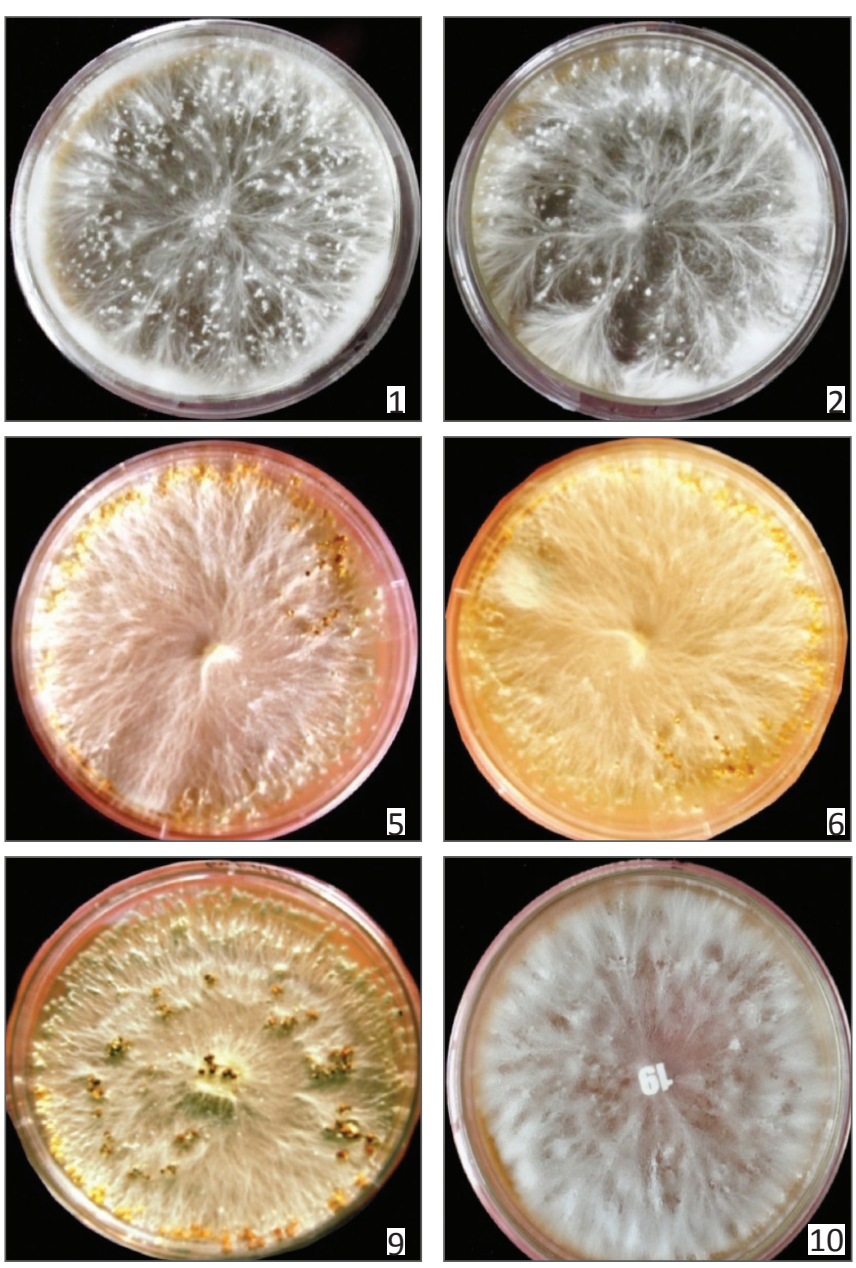

mortality ranges from $33.33-57.57 \%$. In post germination, the highest mortality (57.57\%) was recorded in the isolates of SR1 (Sarsaul, Kanpur) and minimum 33.33\% in isolate of SR5( Mallawa,Hardoi). No symptoms of stem rot appeared
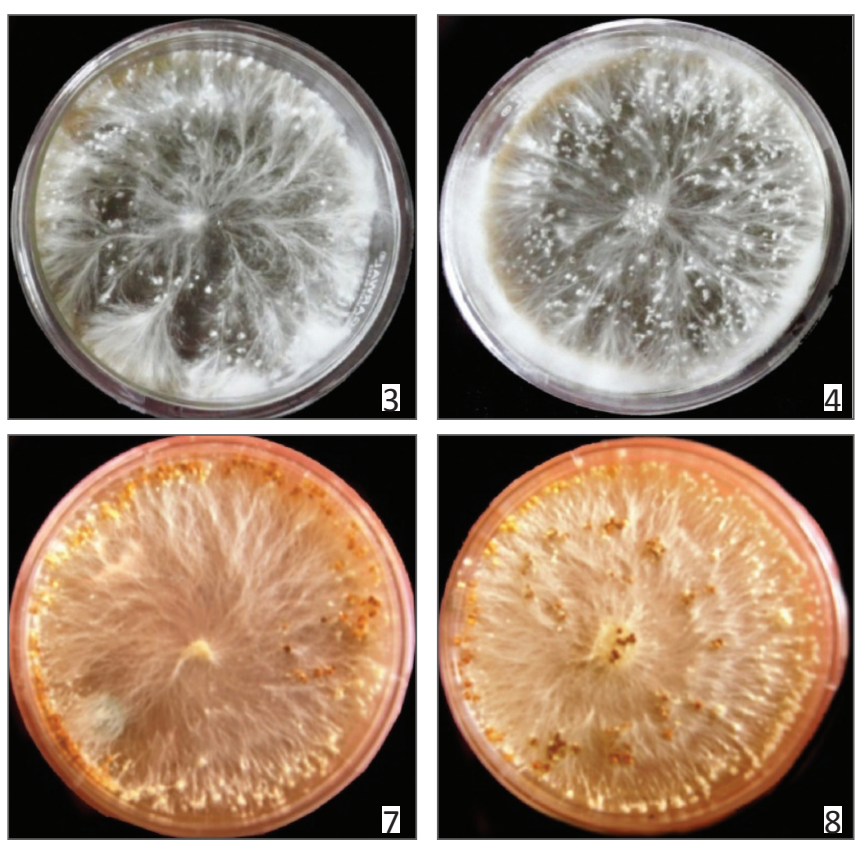

1: SR1 Sarsaul, Kanpur; 2: SR2 Ghatampur, Ramabainagar; 3: SR3 Bindaki, Fatehpur; 4: SR4 Veg. Res.Farm Kalyanpur Kanpur; 5: SR5 Mallawa, Hardoi; 6: SR6 Kucharia, RaeBareli; 7: SR7 Ajgain, Unnao; 8: SR8 Chamad, Aligarh; 9: SR9 Maudaha, Hamirpur; 10: SR10 Barokhar, Banda;

Figure 1: Colony characters of different isolates of Sclerotium rolfsii;

in un-inoculated plant from any isolates. Sennoi et al. (2010) evaluated pathogenecity test of Sclerotium rolfsii causing stem rot of Jerusalem artichoke (Helianthus tuberosus L.). They found that pathogenic variability among ten isolates of S. rolfsii was existing. Palaiah and Adiver (2004) also found the pathogenic variability of 12 isolates of $S$. rolfsii based on the

\begin{tabular}{lccccccc}
\hline \multicolumn{7}{l}{ Table 2: Pathogenic variability of Sclerotium rolfsii isolates on chilli variety Kalyanpur Chaman } & \\
\hline Isolates from different location & NSSP & NSGP & $\begin{array}{c}\text { Avg. seed } \\
\text { germination \% }\end{array}$ & $\begin{array}{c}\text { PGDI } \\
\text { Average height of } \\
\text { seedlings (cm.) }\end{array}$ & NIP & $\begin{array}{c}\text { Disease } \\
\text { incidence (\%) }\end{array}$ \\
\hline SR1 Sarsaul, Kanpur & 40 & 33 & 82.5 & 17.5 & 18.50 & 19 & 57.57 \\
SR2 Ghatampur, Ramabainagar & 40 & 36 & 90.0 & 10.0 & 19.25 & 18 & 50.00 \\
SR3 Bindaki, Fatehpur & 40 & 31 & 77.50 & 22.5 & 19.00 & 15 & 48.38 \\
SR4 Veg. Res.Farm Kalyanpur Kanpur & 40 & 34 & 85.0 & 15.0 & 19.25 & 13 & 38.23 \\
SR5 Mallawa, Hardoi & 40 & 33 & 82.5 & 17.5 & 19.25 & 17 & 51.51 \\
SR6 Kucharia, RaeBareli & 40 & 36 & 90.0 & 10.0 & 18.00 & 12 & 33.33 \\
SR7 Ajgain, Unnao & 40 & 35 & 87.5 & 12.5 & 19.25 & 18 & 51.42 \\
SR8 Chamad, Aligarh & 40 & 34 & 85.0 & 15.0 & 19.00 & 16 & 47.05 \\
SR9 Maudaha, Hamirpur & 40 & 32 & 80.0 & 20.0 & 19.00 & 15 & 48.87 \\
SR10 Barokhar, Banda & 40 & 33 & 82.5 & 17.5 & 19.75 & 17 & 51.51 \\
\hline
\end{tabular}

NSSP: No. of seeds sown pot ${ }^{-1}$; NSGP: No. of seeds germinated pot $^{-1}$; PGDI: Pre germination disease incidence (\%); NIP:

No. of infected plants 
pathogenecity of the isolates on the host, They grouped the isolates into two on the basis of seedling mortality.

\section{Conclusion}

Isolates of S. rofsii, collected from ten different locations of Uttar Pradesh showed their variability in term of morphological, cultural, sclerotia production and pathogenic indicating that variability is exist among the isolates.

\section{References}

Akram, A., Iqbal, S.M., Qureshi, A.R., Rauf, C.A., 2007. Variability among the isolates of Sclerotium rolfsii associated with collar rot disease of chick pea in Pakistan. Mycopathologia 5(1), 23-28.

Chestler, K.S., 1950. Plant disease losses: their appraisal and interpretation. Plant Disease Reporter 193, 189-192.

Darakhshanda, K., Azam, F., Hassan, A., Ansar, M., Asad, M.J., Khanum, A., 2007. Comparative growth, morphological and molecular characterization of indigenous Sclerotium rolfsii strains isolated from different locations of Pakistan. Pakistan Journal of Botany 39(5), 1849-1866.

Kochi, G.K., 2005. The Hindu business line: chilli export touch all-time high. The Hindu group of Publications, 1-3.

Lukose, C.M., Kadvani, D.L., Dangaria, C.J., 2003. Bulb and stem rot of garlic and chili. Indian Phytopatholog, 56(2), 237.

Palaiah, P., Adiver, S.S., 2004. Bio chemical and pathogenic variation in isolates of $S$. rolfsii causing stemrot of ground nut. Karnataka Journal of Agricultural Sciences 17(4), 843-845.

Parthasarathy, V.A., Kandiannan, K., 2010. Bio diversity of different spices. The Hindu Survey of Indian Agriculture, Chennai, 37.

Prabhu, H.V., Patil, P.V., 2005. Morphological, biochemical and pathogenic variation among Sclerotium rolfsii isolates of soybean. Karnataka Journal of Agricultural Sciences 18(4), 990-994.

Sennoi, R., Jogloy, S., Saksirirat, W., Patanothai, A., 2010. Pathogenecity test of Sclerotium. rolfsii a causal agent ofJerusalem artichoke (Helianthus tuberosus L.) stem rot. Asian Journal of Plant Science 9(5), 281-284.

Serra, I.M., de, S., da Silva, G.S., 2005. Biological and physiological characterization of Sclerotium rolfsii isolates, obtained from green pepper in the state of Maranhao. Fitopatologia Brasileira 30(1), 61-66.

Weber, G.F., 1931. Blight of carrots caused by Sclerotium rolfsii with geographic distribution and host range of the fungi. Phytopathology 21, 1129-1140. 